\title{
BMJ Open Cohort profile: the Health of Philippine Emigrants Study (HoPES) to examine the health impacts of international migration from the Philippines to the USA
}

\author{
A B de Castro (D) , ${ }^{1}$ Anna K Hing, ${ }^{2}$ Nanette R Lee, ${ }^{3}$ Maria Midea M Kabamalan, ${ }^{4}$ \\ Karen Llave, ${ }^{2}$ Catherine M Crespi, ${ }^{5}$ May Wang, ${ }^{2}$ Gilbert Gee ${ }^{2}$
}

To cite: de Castro AB, Hing AK, Lee NR, et al. Cohort profile: the Health of Philippine Emigrants Study (HoPES) to examine the health impacts of international migration from the Philippines to the USA. BMJ Open 2019;9:e032966. doi:10.1136/ bmjopen-2019-032966

- Prepublication history for this paper is available online. To view these files, please visit the journal online (http://dx.doi org/10.1136/bmjopen-2019032966).

Received 16 July 2019 Revised 20 September 2019 Accepted 15 October 2019

Check for updates

(C) Author(s) (or their employer(s)) 2019. Re-use permitted under CC BY-NC. No commercial re-use. See rights and permissions. Published by BMJ.

For numbered affiliations see end of article.

Correspondence to

Dr A B de Castro;

butchdec@uw.edu

\section{ABSTRACT}

Purpose The Health of Philippine Emigrants Study (HOPES) longitudinally investigates over 3 years whether migrating from the Philippines to the USA results in increased risk for obesity relative to non-migrants in the Philippines. The study is designed to test the healthy immigrant hypothesis by collecting health measures from migrants starting from a pre-migration baseline and enrolling a non-migrant cohort matched on age, gender and education for comparison.

Participants A migrant cohort $(\mathrm{n}=832 ; 36.5 \%$ of eligible individuals) was recruited from clients of the Commission on Filipinos Overseas prior to exiting the Philippines. A non-migrant cohort $(\mathrm{n}=805 ; 68.6 \%$ eligible individuals) was recruited from community households in municipalities throughout the cities of Manila and Cebu. By intention, these two cohorts are comparable demographically, including urban/rural status of residency in the Philippines at baseline.

Findings to date At baseline, compared with nonmigrants, migrants report significantly better self-rated health and less depression, and have significantly larger hip circumference and lower waist-to-hip ratio, as well as significantly higher mean systolic blood pressure and higher mean level of apolipoprotein B. Baseline results can offer insight into the health status of both migrant and non-migrant populations and may be useful for obesity prevention efforts.

Future plans Longitudinal data collection is scheduled to be completed in December 2020 when the final data collection wave (36 months after baseline) will conclude. Both migrant and non-migrant cohorts will be maintained beyond the current prospective study, so long as research funding allows and emerges for new study questions. Findings from future longitudinal analyses can inform the need and design of health-related/relevant interventions, whether clinical, behavioural, educational, or policy, that can be implemented at the individual or population level.

\section{INTRODUCTION}

The prevailing view of the immigrant health literature asserts that immigrants arrive in the destination country with better health

\section{Strengths and limitations of this study}

- A cohort of migrants is enrolled into the study starting with data collection at a pre-migration baseline in the country of origin and will be followed prospectively post-migration into the destination country.

- A cohort of non-migrants matched on gender, age, education and urbanicity in the country of origin was enrolled providing opportunities for comparative data analyses.

- Data collection involves subjective and objective biological measures of health status, including dried blood spots that are frozen creating future opportunities for laboratory assays.

- The non-migrant cohort is not representative of the general population as the study objective is for them to be demographically similar to the migrant cohort.

- As prospective follow-up continues, there is a possibility for participant attrition, including because of continued migration domestically and internationally among both the migrant and non-migrant cohorts.

status relative to their same race/ethnicity counterparts born in that country. However, this health advantage has been observed to decline over time with duration in the new country. Research has documented this phenomenon across a variety of physical and mental health outcomes, as well as population groups. ${ }^{1-6}$ In the USA context, immigrants originating from developing countries often exhibit the immigrant health paradox, ${ }^{7-9}$ referring to the contradiction that immigrants generally have better health than USA born individuals who presumably have access to better healthcare services, reside in better environmental conditions and have better opportunities for employment and education. As well, the phrase healthy immigrant hypothesis has been coined to suggest that immigrants generally have better health as 
a function of higher social class (eg, having education, employability and fiscal resources) compared with others in their country of origin, which positions them with the prospect and opportunity to emigrate. While a body of research has informed these perspectives, the preponderance of studies have not been designed to thoroughly investigate them. More specifically, conventional understanding of immigrant health has been premised on cross-sectional studies using self-report survey data collected after arrival in the USA and without a comparison group in the country of origin. The Health of Philippine Emigrants Study (HoPES) was created to address these major limitations in the field of immigrant health by collecting both survey and objective health measures starting from a pre-migration baseline and enrolling a non-migrant cohort in the country of origin matched on age, gender and education.

Filipinos have a long history of migration to the USA, dating back to the late 1500 s and continuing over subsequent centuries, with migration at various times tied to labour, political and military service reasons. In 2016, there were 4.1 million Filipinos in the USA, approximately half of whom were immigrants. ${ }^{10}$ As such, Filipino immigrants are a significant population group to explore the health effects of migration. A well-documented health issue among Filipinos in the USA, as well as in the Philippines, is obesity and concomitant chronic health conditions such as hypertension, diabetes and cardiovascular disease. ${ }^{11-16}$ HoPES principally examines changes in dietary patterns and body weight in the context of migration. A popular hypothesis is that immigrants become acculturated to USA lifestyles and behaviours, including eating larger food portion sizes, consuming more convenient processed, unhealthy fast foods and being more sedentary. ${ }^{17-21}$ Immigrants are also exposed to stressors associated with living in a new country (eg, struggling with employment and having low income and socioeconomic status, discrimination and separation from family and friends in the country of origin) which may prompt feelings of stress and lead to unhealthy dietary practices as well as adversely impact metabolism. ${ }^{22-25}$ Other factors may also play into weight gain among immigrants, such as epigenetics (ie, individuals born in lower-income countries to undernourished mothers may be metabolically prepared to store calories as fat for food scarce environments, but then are susceptible to weight gain after arrival in a country environment high in calories, fat and sugars) and physical activity (ie, immigrants may participate in less leisure physical activity but more work physical activity than those born in the destination country). ${ }^{25}{ }^{26}$ However, whether risk of unhealthy eating and weight gain can be attributed solely to the immigrant experience has not been conceptualised through the lens of globalisation. Indeed, rates of obesity have been rising worldwide, including the Philippines. ${ }^{27-29}$ Accordingly, the overarching empirical question that HoPES seeks to answer is whether migrating to the USA results in increased risk for obesity (losing the healthy immigrant advantage) or if this risk would have been the same had an immigrant remained in the Philippines.

\section{COHORT DESCRIPTION}

HoPES includes a migrant cohort and a non-migrant cohort. The migrant cohort consists of emigrants with legal permission to exit the Philippines for permanent residency in the USA. Migrant cohort participants were enrolled starting at a pre-migration baseline before departing the Philippines and will be followed prospectively after arriving in the USA up to 3years. These migrant participants were recruited onsite at either the Manila or Cebu office of the Commission on Filipinos Overseas (CFO), the national Philippine government agency that oversees legal migration and where legal emigrants must register and process their exit from the Philippines. Trained research staff approached and screened individuals at the CFO locations for study eligibility: aged 20-59 years; departing the Philippines for the USA within 3 months; ability to speak English, Tagalog or Cebuano and not known to be pregnant (as this study prospectively assesses weight gain). From a total of 3412 individuals approached, 2279 met eligibility criteria, and 832 (36.5\% of those eligible) consented and enrolled in the study. While there were no target numbers for the migrant cohort by gender, age and education, distributions along these categories ended up reflecting similar demographic profiles of the recent immigrant Filipino population in the USA. For example, according to the 2011-2013 American Community Survey (https://www.census.gov/programssurveys/acs), among immigrant Filipinos who have been in the USA for less than 2years, $11 \%$ are men aged 20-34 with a college education, which is the same percentage of this same group in the HoPES migrant cohort. Additional details are reported elsewhere. ${ }^{30}$

The second cohort consists of non-migrants who remain in the Philippines. Recruitment of this non-migrant cohort was based on stratified random sampling of households using three strata: Metro Manila (urban), Cebu (urban) and Cebu (rural). For each of these stratum, barangay (smallest administrative government division, somewhat like a census tract) were sampled with probability proportional to population size. Within each selected barangay, cluster sampling of households was conducted, then individuals were sampled within each household. Non-migrants were screened with the same age, language and pregnancy inclusion criteria as migrants, with additional criteria of having resided in the barangay for the past 2years and having no plans to move out of the barangay over the next 3years. As non-migrants were sampled, numbers were tracked to achieve comparability to the gender, age, education and urbanicity frequencies of the migrant cohort. Of the 2215 non-migrant individuals approached, 1173 met eligibility criteria, and 805 (68.6\% of those eligible) consented and enrolled in the study.

On recruitment, the purpose and procedures of HoPES was explained to eligible individuals through the informed consent process. Participants were given 
Table 1 Demographic characteristics of HoPES participants and non-participants at time of recruitment and enrolment

\begin{tabular}{|c|c|c|c|c|c|c|}
\hline & \multicolumn{3}{|l|}{ Migrants } & \multicolumn{3}{|l|}{ Non-migrants } \\
\hline & $\begin{array}{l}\text { Participants } \\
(\mathrm{n}=832)\end{array}$ & $\begin{array}{l}\text { Eligible non- } \\
\text { participants } \\
(n=1447)\end{array}$ & $P$ value & $\begin{array}{l}\text { Participants } \\
(\mathrm{n}=805)\end{array}$ & $\begin{array}{l}\text { Eligible non- } \\
\text { participants } \\
(\mathrm{n}=355)\end{array}$ & $P$ value \\
\hline Age in years (mean; SD) & $35.46(11.57)$ & $38.53(11.64)$ & 0.000 & $36.53(11.47)$ & $35.77(10.81)$ & 0.304 \\
\hline Female (number; \%) & $553(66.47)$ & $865(60.15)$ & 0.003 & $548(68.07)$ & $185(50.41)$ & 0.000 \\
\hline Education (number; \%) & & & 0.049 & & & 0.000 \\
\hline High school degree & 170 (20.68) & $247(17.30)$ & & 143 (18.19) & $59(16.43)$ & \\
\hline $\begin{array}{l}\text { Some college or vocational } \\
\text { training }\end{array}$ & $190(23.11)$ & $354(24.79)$ & & $320(40.71)$ & $127(35.38)$ & \\
\hline College degree or higher & 412 (50.12) & $764(53.50)$ & & $222(28.24)$ & $158(44.01)$ & \\
\hline
\end{tabular}

Pearson's $\chi^{2}$ tests were conducted to calculate $p$ values indicating if participant and non-participant groups were statistically different from each another.

HoPES, Health of Philippine Emigrants Study.

opportunity to ask questions and contact information of the research team. Signed consent was obtained from participants for baseline and all subsequent data collection waves. Participants were assured that their participation would be kept confidential, and that data would be de-identified and reported only in the aggregate. Participants were also granted a certificate of confidentiality via the USA National Institutes of Health.

Table 1 provides demographic characteristics at time of recruitment and enrolment of the migrant and nonmigrant participants, as well as those who were eligible but did not participate. Attrition rate for each of the cohorts has not yet been determined because collection of follow-up data is still ongoing, thus we report only on the baseline stage of the study.

For the migrant cohort, pre-migration baseline data (both survey-based and objective, biological measures; see below) was collected by trained research interviewers and nurses between February and September 2017. Subsequent collection of survey data is scheduled after arrival in the USA at 3, 12 and 24 months after baseline and will be conducted by telephone call from a trained research interviewer (because of logistical and budget constraints, since migrants can be located all across the USA). At 36 months after baseline, an in-person home visit will be made by a trained research nurse to collect both survey data and objective, biological measures. For the non-migrant cohort in the Philippines, baseline data (both survey-based and objective, biological measures) was collected by trained research interviewers and nurses between May and September 2017. Follow-up data collection for non-migrants will follow the same pattern as for migrants, except without the 3-month follow-up, and will be done via in-person home visits by trained research interviewers and nurses unless participant residence at the 12 and 24-month mark necessitates conducting by phone.

Baseline data collection for both the migrant and nonmigrant cohorts was conducted in the Philippines. For migrants, this was done in private office spaces in the
CFO buildings in Manila and Cebu. For non-migrants, this was done with in-home visits in community settings. Table 2 lists the types and topics of data collected at baseline. Self-report measures were collected via intervieweradministered survey. Migrants and non-migrants were asked the same survey questions, with migrants being asked an additional set of questions related to migration. Objective measures (eg, height, weight, hip and waist circumferences, blood pressure) were obtained by trained nurses. A point-of-care device was used to measure a non-fasting lipid panel. Dried blood spots (DBS) were collected for laboratory analysis of $\mathrm{C}$-reactive protein (CRP) and apolipoprotein B (ApoB) levels. DBS specimens are being kept in frozen storage $\left(-80^{\circ} \mathrm{C}\right)$ and are available for other additional laboratory assay analyses in the future. The survey questions will be repeated for each follow-up data collection wave (as above), with phrasing modifications made to fit the post-migration context for the migrant cohort. As mentioned, objective, biological measures are collected only at baseline and 36 months later.

\section{Patient and public involvement}

No patient or public involvement.

\section{FINDINGS TO DATE}

Table 3 displays initial univariate estimates (unweighted and weighted) across a variety of self-report and objective measures indicative of baseline health status for both the migrant and non-migrant cohorts. At baseline, migrants report significantly better self-rated health and fewer depressive symptoms, and have significantly larger hip circumference and lower waist-to-hip ratio, as well as significantly higher mean systolic blood pressure and higher mean level of ApoB. For migrants, the principal reasons for emigrating were to join family members already in the USA $(n=770)$ and for employment $(n=62)$. 
Table 2 HoPES measures obtained at baseline for migrant and non-migrant cohorts

\section{Self-report measures}

Health status

Self-rated health, chronic health conditions (MOS), medication use, depressive symptoms (Patient-Reported Outcomes Measurement Information System); cognitive impairment; homesickness

Health behaviours

Physical activity (International Physical Activity Questionnaire), smoking (Centers for Disease Control and Prevention Behavioral Risk Factor Surveillance System), alcohol consumption (Behavioral Risk Factor Surveillance System), sleep quality and duration; help seeking

\begin{tabular}{|c|c|}
\hline Diet & Food frequency questionnaire, food procurement and insecurity, dietary acculturation \\
\hline Stress & Perceived stress, acculturative stress, unfair treatment \\
\hline Culture & $\begin{array}{l}\text { Filipino attitudes and beliefs, social identity, language use and proficiency (including } \\
\text { English) }\end{array}$ \\
\hline Socioeconomic position & $\begin{array}{l}\text { Currently employed, current occupation and job duties, personal income, financial strain, } \\
\text { remittances }\end{array}$ \\
\hline Social networks & Family and friends in the USA and Philippines, social isolation, social capital \\
\hline Migration (migrant cohort only) & $\begin{array}{l}\text { Visa type, family accompaniment, preparation, reasons for migrating, views about USA, } \\
\text { job waiting in USA }\end{array}$ \\
\hline \multicolumn{2}{|l|}{ Objective measures } \\
\hline Anthropometrics & $\begin{array}{l}\text { Height (Charder brand stadiometer model HM200P), weight (Tanita Corporation digital } \\
\text { scale model BC-541 N), waist circumference and hip circumference (average of three } \\
\text { readings; Weight and Measure brand tape measure model CAN150) }\end{array}$ \\
\hline
\end{tabular}

HoPES, Health of Philippine Emigrants Study.

Migrants settled across all regions of the USA, with the top states being California, Texas, Washington, Hawaii, Florida and Nevada, thus far.

\section{STRENGTHS AND LIMITATIONS}

HoPES is one of the few longitudinal studies of migration and health that has enrolled participants starting from a pre-migration baseline phase in one country (Philippines) and followed them into a post-migration period in another (USA). Other known studies have followed migrants from Mexico to the USA and migrants from Russia and Ukraine to Israel. ${ }^{41-33}$ Our study has the added feature of following a migrant cohort across continents from Asia to North America. Conventional understandings of immigrant health have relied principally on data collected after migration, for example the National Latino and Asian American Study (USA) ${ }^{34}$ and the Research on Obesity and Diabetes among African Migrants project (Germany, the Netherlands, United Kingdom and Ghana allowing for comparison with non-migrants in the country of origin). ${ }^{26}$ The New Immigrant Study does follow prospectively a cohort of adult and child immigrants in the USA but also captures only postmigration data. ${ }^{35}$ Importantly, these and other studies like them offer valuable insights about a range of health status outcomes and experiences of immigrants, including disparities in health relative to populations native to the destination country. While findings from these studies provide the basis for attending to the health needs of immigrant communities that bear disproportionate burdens of illness, this established body of literature warrants a more expansive view of immigrant health. Notably, prospective examination of health inclusive of the pre-migration period can provide a more complete picture of transitions in health throughout the dynamic nature of migration.

As mentioned earlier, the demographic profile of our migrant cohort is very similar to that of the recent immigrant Filipino population in the USA, per the 2011-2013 American Community Survey. A group of non-migrants (similar in age, gender and education) in the country of origin is enrolled, which other studies of migration and health have not included, providing opportunities for comparative data analyses. For migrants, having started from a pre-migration baseline, data represent health status and life experiences prior to migration. Data, for both migrants and non-migrants, include objective, biological measures of health status, in addition to 


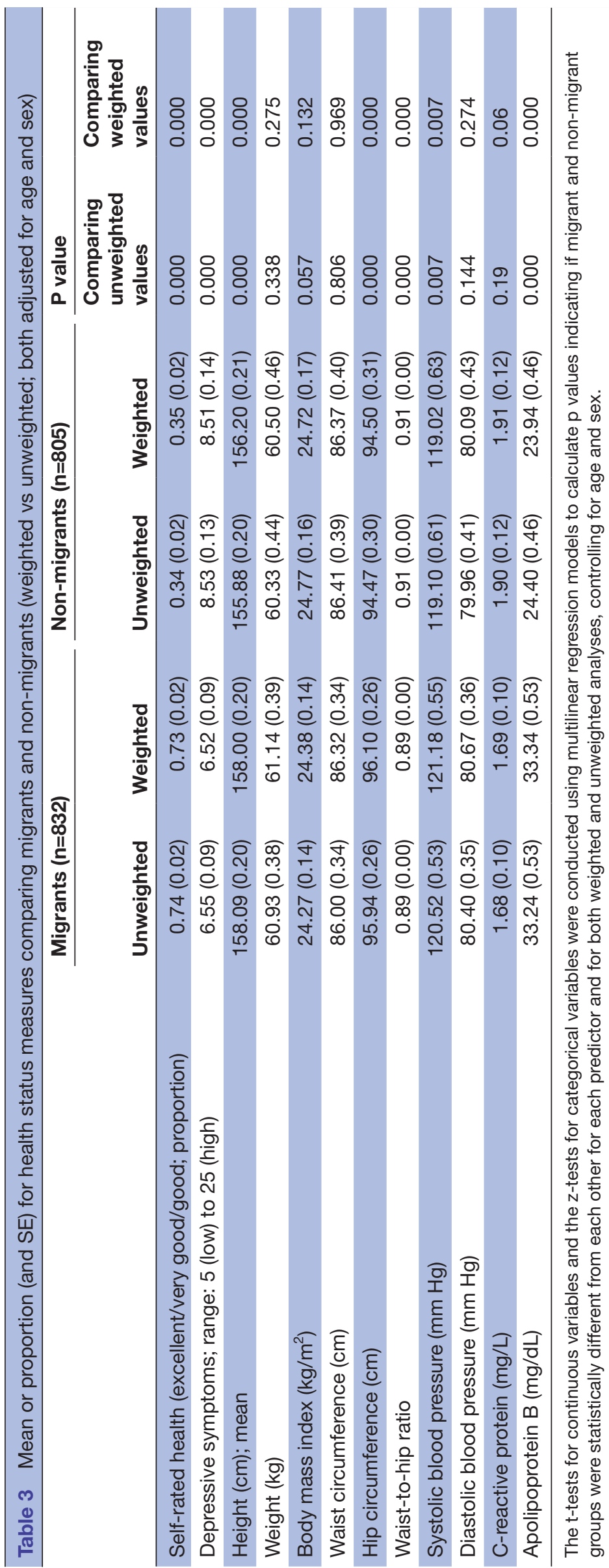


self-report responses that, to our knowledge, have not been collected in other longitudinal studies of migration. The collection and frozen banking of DBS creates future opportunities for laboratory analyses of emerging and yet to be developed assays. Also, meticulous efforts were undertaken to assure linguistic and cultural appropriateness of survey instruments, including data obtained through a food frequency questionnaire tailored to Filipino foods and diet. Additionally, for each participant, residential address is collected at each follow-up wave, allowing for geocoding and analyses integrating geographical information system data.

Due to the nature of the study, the non-migrants are purposefully not representative of the general population of the Philippines. This was due to our aim to evaluate the effect of migration as a 'treatment'. Similar to a randomised clinical trial, it is desirable to have the two cohorts similar on key characteristics at baseline. Thus, our objective for the non-migrant cohort was to enrol a group similar in characteristics (age, gender, education) to the migrant cohort, which would then render the nonmigrant sample not representative of the general population. While the overall sample sizes for each cohort are sufficiently large for our study purposes, it may be limiting for analyses focused on specific subgroups (eg, only women with less than a high school education).

Another potential weakness relates to participation rates and potential for sampling bias. Comparing participants to eligible non-participants, per table 1, a few demographic differences were statistically significant. For example, migrant participants were older than migrants who were eligible but did not participate; non-migrant participants tended to be more educated than nonmigrants who were eligible but did not participate; and for both migrant and non-migrant cohorts, there were more women among participants than among eligible non-participants.

With any cohort study, attrition is a concern, particularly when participants are in a state of geographical movement across countries (migrants) and, likely, within country (migrants after arriving in the USA and non-migrants in the Philippines). It is possible, over the course of the study, that migrant participants may return to the Philippines or re-locate to other countries for periods of time and that non-migrant participants may become migrants themselves (whether to the USA or elsewhere). While this poses additional challenges, if such cases emerge and are retained, their data can yield potentially interesting, unanticipated findings about continued migration transitions. Since we currently report only on the baseline stage of this study, retention rates and mobility patterns over the course of the study have yet to unfold. Strategies, such as phone calls, a newsletter, social media and birthday greetings, to promote retention have been implemented. Also, we intentionally over-sampled to account for attrition. Lastly, our study does not include a third cohort group of US born Filipinos, which would have provided another comparison group to more fully examine the immigrant health paradox.

\section{COLLABORATION}

Researchers wishing to work with HoPES data can contact the co-principal investigators- $\mathrm{GG}$ and $\mathrm{ABdC}$ - to discuss analysis ideas and possible collaborative efforts. Requests are invited for studies that examine the variety of crosssectional and longitudinal associations between sociodemographic characteristics, geographical locations (eg, migration patterns, neighbourhood/community factors), stressors, cultural shifts and both subjective and objective measures of health and health behaviours (including and beyond obesity risk-related outcomes) that characterise how differential burdens of illness/disease play out in the context of migration and globalisation. Also, since DBS are frozen and stored, collaborations involving studies with laboratory analysis of analytes other than CRP and ApoB are of interest.

A data user agreement is available for interested researchers to specify a working title of their proposed project; a 1-2 paragraph abstract that articulates a research question, hypotheses and supporting rationale; a description of the analysis plan, including the specific statistical techniques to be used; the list the specific variables needed for the analysis, including identifying dependent versus independent variables, and control variables and a statement of dissemination plans, including prospective journals and conference meetings where the analysis will be reported. The co-principal investigators will consider the request and determine its approval. The data user agreement also delineates a list of conditions that users must agree to; such as not sharing or distributing the data without prior authorisation from the co-principal investigators, using the requested data only according to the proposed use, sharing with the co-principal investigators documentation of new variables of major study constructs and prompt notification of submissions and acceptances for presentations and publications.

\section{FURTHER DETAILS}

HoPES would not have been possible without the imaginative ingenuity, collaborative spirit and tireless efforts from multiple sources. The interdisciplinary team consists of researchers and staff from the USA and the Philippines with a shared interest and vision to advance the health of immigrant populations. The co-principal investigators of HoPES are GG and ABdC. In addition to the authors, others making important contributions through their knowledge, skills and time were Anna Vivas, Elma P. Laguna, Christian Joy P. Cruz, Tita Lorna Perez, Delia B. Carba, Nikola Mae Y. Belarmino, Klarriness P. Tanalgo, Vanessa Medina and all members of the data collection staff. The cooperation, approval, support and assistance from staff of the Commission on Filipinos Overseas, namely Regina Galias, Ivy Miravalles, Kimberly 
Dizon, Golda Myra Roma and Paul Vincent Avecilla, made it possible to recruit and enrol migrant participants. We also greatly appreciate permissions granted and facilitated by government officials in local municipal jurisdictions to enter communities to recruit and enroll non-migrant participants from community households. And, we express our deep appreciation to all of the HoPES participants who generously provided their time and willingness for us to collect data measures. Lastly, we dedicate this paper to Eularito A. Tagalog in memory of his truly incomparable friendship and many selfless acts to help make this research project a reality.

\section{Author affiliations}

${ }^{1}$ Department of Child, Family, and Population Health Nursing, School of Nursing, University of Washington, Seattle, Washington, United States

${ }^{2}$ Department of Community Health Sciences, Fielding School of Public Health, University of California, Los Angeles, California, United States

${ }^{3}$ Office of Population Studies Foundation, Inc, University of San Carlos, Cebu City, Philippines

${ }^{4}$ University of the Philippines Population Institute, College of Social Sciences and Philosophy, University of the Philippines Diliman, Quezon City, Philippines ${ }^{5}$ Department of Biostatistics, Fielding School of Public Health, University of California, Los Angeles, California, United States

Contributors $\mathrm{ABdC}$ led the conceptualisation and writing of this paper with writing and statistical analysis assistance from AKH, CMC, GG, MMMK, NRL and MW collaborated to conceptualize and execute the overall HoPES project and KL managed HoPES project operations. All authors assisted with the writing content.

Funding Primary funding for HoPES was provided by the US National Institutes of Health - Eunice Kennedy Shriver National Institute of Child Health and Human Development (1R01HD083574-01A1), and, prior pilot funding was provided by the US National Institutes of Health - National Cancer Institute (1R21CA137297-01A1) and the California Center for Population Research at the University of California, Los Angeles (P2C-HD041022).

Competing interests None declared.

Patient consent for publication Not required.

Ethics approval UCLA Office of the Human Research Protection Program. Application \#16-001159. Ethics review and approval to conduct HoPES were granted by the institutional review boards at the University of California, Los Angeles (USA), and the University of San Carlos (Cebu, Philippines).

Provenance and peer review Not commissioned; externally peer reviewed. Data availability statement Data are available upon reasonable request.

Open access This is an open access article distributed in accordance with the Creative Commons Attribution Non Commercial (CC BY-NC 4.0) license, which permits others to distribute, remix, adapt, build upon this work non-commercially, and license their derivative works on different terms, provided the original work is properly cited, appropriate credit is given, any changes made indicated, and the use is non-commercial. See: http://creativecommons.org/licenses/by-nc/4.0/.

ORCID iD

A B de Castro http://orcid.org/0000-0002-1293-7015

\section{REFERENCES}

1 Antecol H, Bedard K. Unhealthy assimilation: why do immigrants converge to American health status levels? Demography 2006;43:337-60.

2 Argeseanu Cunningham S, Ruben JD, Venkat Narayan KM. Health of foreign-born people in the United States: a review. Health Place 2008;14:623-35.

3 Frisbie WP, Cho Y, Hummer RA. Immigration and the health of Asian and Pacific Islander adults in the United States. Am J Epidemiol 2001;153:372-80.

4 Goldman N, Pebley AR, Creighton MJ, et al. The consequences of migration to the United States for short-term changes in the health of Mexican immigrants. Demography 2014;51:1159-73.
5 Ro A. The longer you stay, the worse your health? A critical review of the negative acculturation theory among Asian immigrants. Int $J$ Environ Res Public Health 2014;11:8038-57.

6 Fuller-Thomson E, Noack AM, George U. Health decline among recent immigrants to Canada: findings from a nationallyrepresentative longitudinal survey. Can J Public Health 2011;102:273-80.

7 Alarcón RD, Parekh A, Wainberg ML, et al. Hispanic immigrants in the USA: social and mental health perspectives. Lancet Psychiatry 2016;3:860-70.

8 Franzini L, Ribble JC, Keddie AM. Understanding the Hispanic paradox. Ethn Dis 2001;11:496-518.

9 Markides KS, Coreil J. The health of Hispanics in the southwestern United States: an epidemiologic paradox. Public Health Rep 1986;101:253-65.

10 Zong J, Batalova J. Filipino immigrants in the United States. migration information source, 2018. Available: https://www. migrationpolicy.org/article/filipino-immigrants-united-states [Accessed 14 Jul 2019].

11 Abesamis CJ, Fruh S, Hall H, et al. Cardiovascular health of Filipinos in the United States: a review of the literature. J Transcult Nurs 2016;27:518-28.

12 Du Y, Shih M, Lightstone AS, et al. Hypertension among Asians in Los Angeles County: findings from a multiyear survey. Prev Med Rep 2017;6:302-6.

13 Lee JWR, Brancati FL, Yeh H-C. Trends in the prevalence of type 2 diabetes in Asians versus whites: results from the United States National health interview survey, 1997-2008. Diabetes Care 2011;34:353-7.

14 Singh GK, Lin SC. Dramatic increases in obesity and overweight prevalence among Asian subgroups in the United States, 1992-2011. ISRN Prev Med 2013;2013:1-12.

15 Staimez L, Weber M, Narayan K, et al. A systematic review of overweight, obesity, and type 2 diabetes among Asian American subgroups. Curr Diabetes Rev 2013;9:312-31.

16 Ye J, Rust G, Baltrus P, et al. Cardiovascular risk factors among Asian Americans: results from a national health survey. Ann Epidemiol 2009;19:718-23.

17 Ayala GX, Baquero B, Klinger S. A systematic review of the relationship between Acculturation and diet among Latinos in the United States: implications for future research. J Am Diet Assoc 2008;108:1330-44.

18 Kandula NR, Lauderdale DS, time L. Leisure time, Non-leisure time, and occupational physical activity in Asian Americans. Ann Epidemiol 2005;15:257-65.

19 Serafica RC. Dietary acculturation in Asian Americans. J Cult Divers 2014;21:145-51.

20 Tovar A, Boulos R, Sliwa S, et al. Baseline Socio-demographic Characteristics and Self-Reported Diet and Physical Activity Shifts Among Recent Immigrants Participating in the Randomized Controlled Lifestyle Intervention: "Live Well". J Immigrant Minority Health 2014;16:457-65.

21 Zan H, Fan JX. Reporting more but moving less? the complex relationship between acculturation and physical activity among US adults. Am J Health Promot 2018;32:446-52.

22 Finch BK, Catalano RC, Novaco RW, et al. Employment frustration and alcohol abuse/dependence among labor migrants in California. $J$ Immigr Health 2003;5:181-6.

23 Gee GC, Ro A, Gavin A, et al. Disentangling the effects of racial and weight discrimination on body mass index and obesity among Asian Americans. Am J Public Health 2008;98:493-500.

24 Tovar A, Must A, Metayer N, et al. Immigrating to the US: what Brazilian, Latin American and Haitian women have to say about changes to their lifestyle that may be associated with obesity. $J$ Immigrant Minority Health 2013;15:357-64.

25 Murphy M, Robertson W, Oyebode O. Obesity in international migrant populations. Curr Obes Rep 2017;6:314-23.

26 Agyemang C, Beune E, Meeks K, et al. Rationale and crosssectional study design of the research on obesity and type 2 diabetes among African migrants: the RODAM study. BMJ Open 2014;4:e004877.

27 Abarca-Gómez L, Abdeen ZA, Hamid ZA, et al. Worldwide trends in body-mass index, underweight, overweight, and obesity from 1975 to 2016: a pooled analysis of 2416 population-based measurement studies in 128.9 million children, adolescents, and adults. Lancet 2017;390:2627-42.

$28 \mathrm{Ng} \mathrm{M}$, Fleming T, Robinson M, et al. Global, regional, and national prevalence of overweight and obesity in children and adults during 1980-2013: a systematic analysis for the global burden of disease study 2013. Lancet 2014;384:766-81. 
29 Obesity Update 2017. The organisation for economic co-operation and development (OECD), 2017. Available: https://www.oecd.org/els/ health-systems/Obesity-Update-2017.pdf [Accessed 14 Jul 2019].

30 Gee GC, de Castro AB, Crespi CM, et al. Health of Philippine emigrants study (HoPES): study design and rationale. BMC Public Health 2018;18:771.

31 Breslau J, Borges G, Tancredi DJ, et al. Health selection among migrants from Mexico to the U.S.: childhood predictors of adult physical and mental health. Public Health Rep 2011;126:361-70.

32 Tartakovsky E. A longitudinal study of acculturative stress and homesickness: high-school adolescents immigrating from Russia and Ukraine to Israel without parents. Soc Psychiatry Psychiatr Epidemiol 2007;42:485-94.
33 Tartakovsky E. Cultural identities of adolescent immigrants: a threeyear longitudinal study including the pre-migration period. $J$ Youth Adolesc 2009;38:654-71.

34 Alegria M, Takeuchi D, Canino G, et al. Considering context, place and culture: the National Latino and Asian American study. Int $J$ Methods Psychiatr Res 2004;13:208-20.

35 Jasso G, Massey DS, Rosenzweig MR. The U.S. New Immigrant Survey: overview and preliminary results based on the newimmigrant cohorts of 1996 and 2003. In: Morgan B, Nicholson $\mathrm{B}$, eds. Immigration research and statistics service workshop on longitudinal surveys and cross-cultural survey design: workshop proceedings. London, UK: Crown Publishing, 2005: 29-46. 